\title{
First record in Poland of the Ligurian leafhopper, Eupteryx decemnotata Rey 1891 (Cicadomorpha, Cicadellidae) - an important pest of herbs
}

\author{
Magdalena Lubiarz ${ }^{1 *}$, Krzysztof Musik ${ }^{2}$ \\ ${ }^{1}$ Department of Environmental Protection and Landscape Preservation, The John Paul II Catholic University of Lublin, \\ Konstantynów 1H, 20-708 Lublin, Poland \\ ${ }^{2}$ Department of Zoology, Faculty of Biology and Environmental Protection, University of Silesia, Bankowa 9, 40-007 Katowice, Poland
}

Received: January 21, 2015

Accepted: June 19, 2015

\begin{abstract}
The Ligurian leafhopper (Eupteryx decemnotata Rey 1891) has been recorded for the first time in Poland, in a commercial greenhouse in Warsaw. Individuals were collected from rosemary (Rosmarinus officinalis L.). Intense feeding of this species caused serious damage in the cultivation of rosemary. For this reason, the range extension of this species must be monitored.
\end{abstract}

Key words: economic importance, herbs, important pest, Ligurian leafhopper, new records

\section{Introduction}

Conducting research and collecting new data on the range extension of economically important species have always been matters of the highest priority. Nowadays, with intensely developed transport services, such species can easily and rapidly be spread all over the world. One of the common ways a new area becomes inhabited is by transporting the host plants with oviposited eggs. This is the how the Ligurian leafhopper (Eupteryx decemnotata Rey 1891) managed to arrive in Poland.

During the past three decades, E. decemnotata has colonised nearly the entire area of Central Europe and its range is still expanding. The first record from Germany dates from 1989 (Remane 1995). Later this species was recorded in Switzerland (Günthart 1987), France (Giustina Della and Balasse 1999), Slovenia (Holzinger and Seljak 2001), the British Isles (Maczey and Wilson 2004), and recently also in North America, i.e. California and Florida (Rung et al. 2009).

The Ligurian leafhopper is an oligophagous species and its host plants are mainly aromatic species of Lamiaceae. According to scientific research the Ligurian leafhopper has been found on Rosmarinus officinalis L., Salvia officinalis L., Melissa officinalis L., Origanum majorana L., Thymus vulgaris L., Mentha x piperita L., and Nepeta cataria L. (Nickel and Holzinger 2006).

From the economic point of view, this species can cause serious damage mainly because of its density on the host plants. Eupteryx decemnotata usually feeds in vast numbers, which can weaken or kill the host plant (Nickel and Holzinger 2006). Large-scale cultivation of culinary herbs in greenhouses has only recently begun in Poland.
For this reason, no complex studies on the fauna of these plants have been conducted as yet (Lubiarz et al. 2013).

\section{Materials and Methods}

Individuals of E. decemnotata were collected from rosemary ( $R$. officinalis) grown in commercial greenhouses. These were greenhouses specialised in culinary herb cultivation situated in Warsaw. Due to the commercial character of the greenhouses it was not possible to use a sweep net, instead adult specimens were collected by hand.

Eleven individuals (only females) of E. decemnotata were collected on 26 February 2014, in the city of Lublin, Poland. On 9 May 2014, in Warsaw, 307 individuals (40 $\hat{\jmath} \hat{\sigma}$ and 267 우) were collected. The collected material was deposited in the Department of Zoology, University of Silesia in the city of Katowice, Poland.

\section{Results}

\section{Field identification and hosts}

Eleven females of E. decemnotata were found in Lublin. They were collected from rosemary plants that had been transported from the greenhouses in Warsaw. Subsequently, E. decemnotata specimens were also observed on mint (Mentha sp.), basil (Ocimum basilicum L.), and lemon balm (M. officinalis). The plants were grown in the Department of Environmental Protection and Landscape Preservation, John Paul II Catholic University of Lublin, for conducting research into the feeding behaviour 

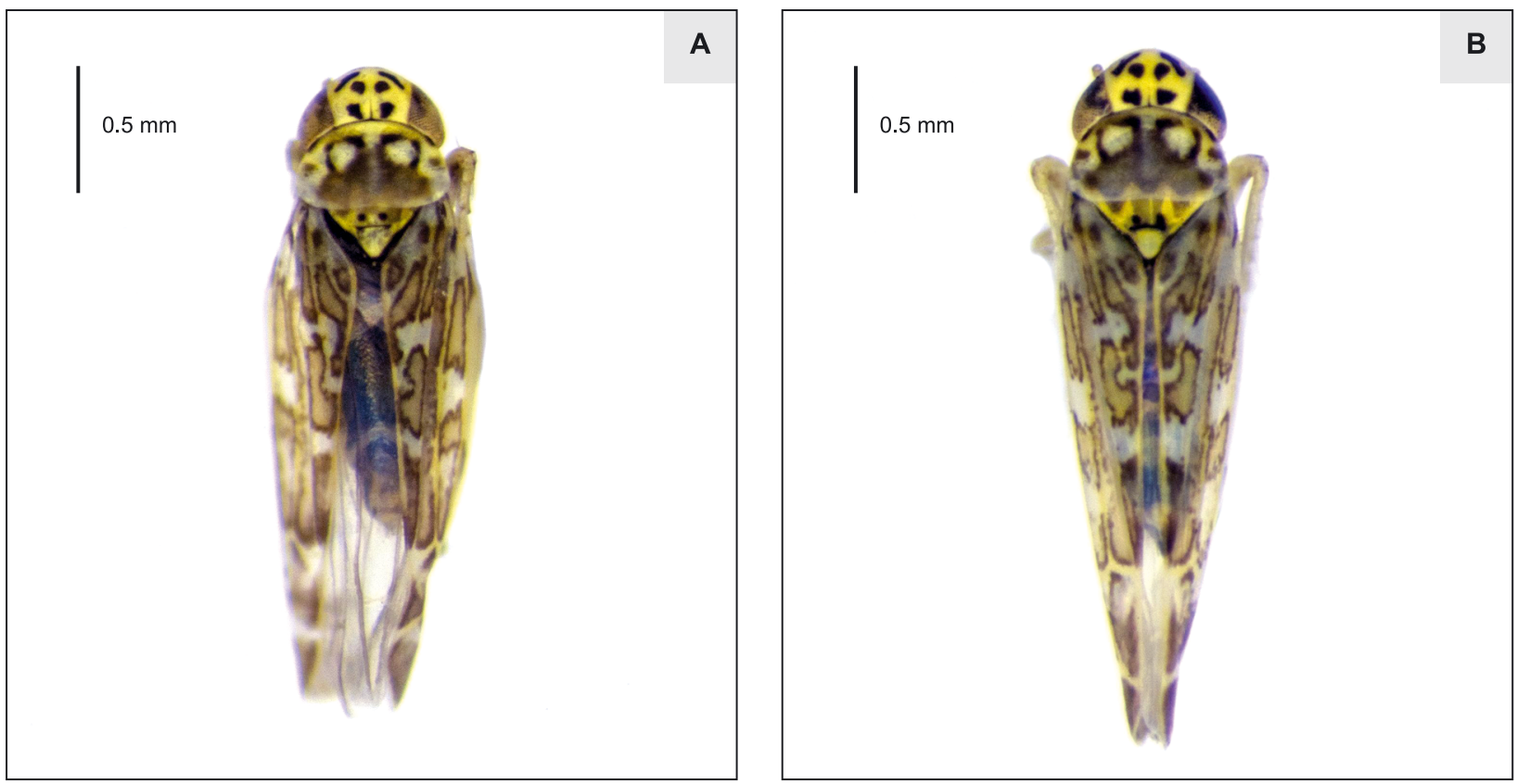

Fig. 1. Male (A) and female (B) of Eupteryx decemnotata
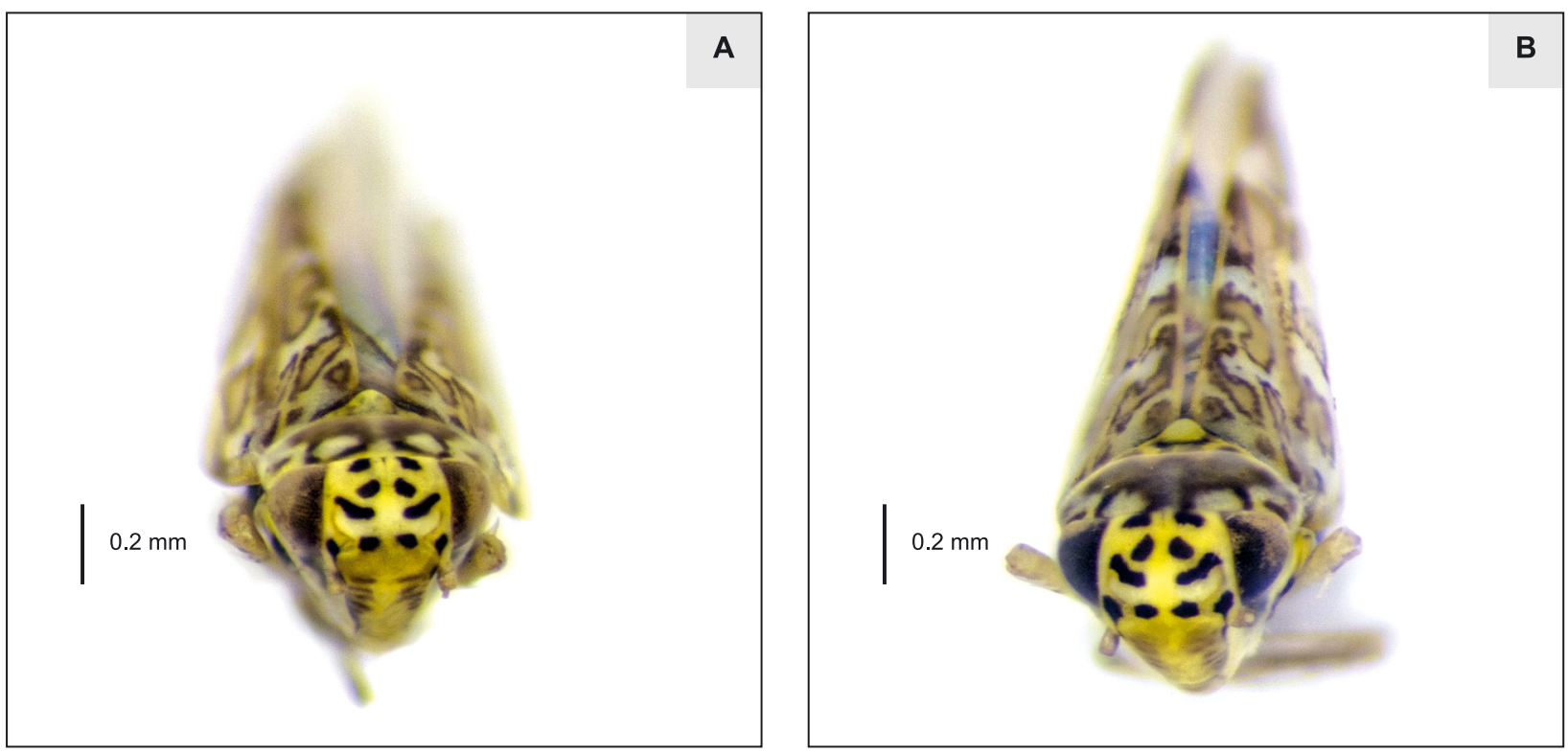

Fig. 2. Head of Eupteryx decemnotata male (A) and female (B)
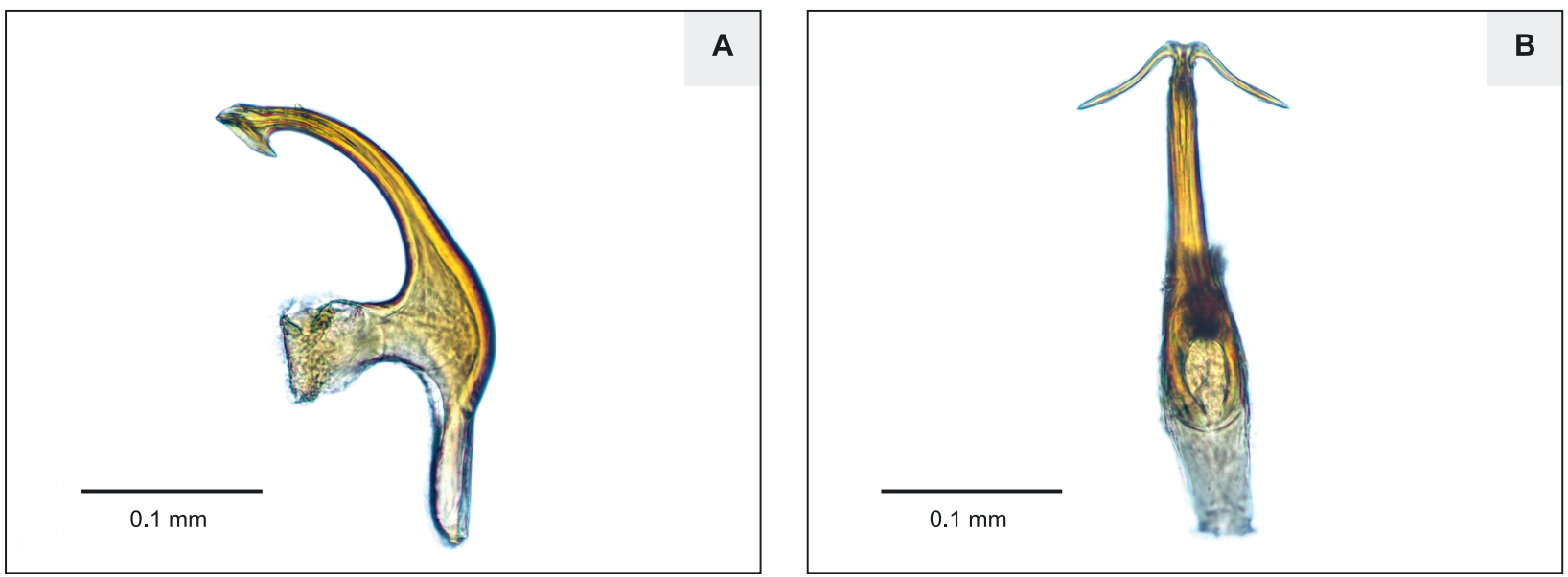

Fig. 3. Aedeagus of Eupteryx decemnotata: A - lateral view; B - ventral view 
of aphids. It was noted that the host plant preferred by E. decemnotata was rosemary. The abundance of E. decemnotata on rosemary was much higher than on the other host plants. During the five weeks that elapsed since the occurrence of the first individuals, E. decemnotata became so abundant that the host plants were seriously damaged and cultivation had to be started anew.

Eupteryx decemnotata is a small, yellowish green leafhopper. There are no differences between the colouration of the male and the female (Fig. 1). The key feature of this species is the number of spots on the head: six spots on the vertex and four spots on the frons, making a total of ten spots (Fig. 2). The aedeagus of this species is distinctive among the Eupteryx genus; it is curved and with serrated lateral ridges at the apical part (Fig. 3A, B).

\section{Damage and economic importance}

The Ligurian leafhopper is an important pest in cultivations of plants from the family Lamiaceae. It is particularly a pest of rosemary ( $R$. officinalis). The feeding of $E$. decemnotata causes serious damage to rosemary plants. Initially leaves turn yellow, then leaves wither and fall. Producers estimate that the feeding of this leafhopper species forces them to destroy as much as $20 \%$ of the plants before they are ready for sale. The results are heavy financial losses.

In order to diminish the abundance of E. decemnotata in the cultivations, herb producers remove the individuals of this species using a vacuum cleaner, since no client is going to buy herbs with numerous insects. Small numbers of the leafhopper species in question, are also collected using yellow sticky traps in greenhouses.

\section{Discussion}

The present study reports the occurrence of the Ligurian leafhopper on plants from the family Lamiaceae. The species mainly settles on rosemary ( $R$. officinalis) and causes serious damage to plants. Similar observations had been made in North America by Rung et al. (2009). It is important to monitor plants from the family Lamiaceae which grow in areas surrounding greenhouses. According to Nickel and Holzinger (2006), the most important host plants of the species growing outdoors include S. officinalis and N. cataria.

Eupteryx decemnotata has distinguishing head coloration. Other closely related species like E. melissae and $E$. thoulessi differ by the number of spots on the head. Eupteryx melissae has three vertex spots and two spots on the frons and $E$. thoulessi has three vertex spots and four spots on the frons. Beside the head colouration, those species can be easily identified by the aedeagus (Biedermann and Niedringhaus 2009).

\section{Conclusions}

1. The new species in Polish fauna - E. decemnotata - is an important pest of plants from the family Lamiaceae.
2. The feeding by E. decemnotata causes damage to colonised plants. Leaves turn yellow and eventually wither and fall.

3. Economic losses caused by E. decemnotata led to a reduction of rosemary cultivation in the studied greenhouses at the beginning of 2015 .

\section{Acknowledgements}

The authors would like to thank Professor Wojciech Goszczyński for his help in the collection of the research material.

\section{References}

Biedermann R., Niedringhaus R. 2009. The Plant- and Leafhoppers of Germany. Identification Key to all Species. Wissenschaftlicher Akademischer Buchvertrieb - Fründ, Scheeßel, Germany, 409 pp.

Giustina Della W., Balasse H. 1999. Gone with the wind: Homoptera Auchenorrhyncha collected by the French network of suction traps in 1994. Marburger Entomologische Publicationen 3 (1): 7-42.

Günthart H. 1987. Für die Schweiz neue und wenig gesammelte Zikaden-Arten (Hom. Auchenorrhyncha), 2. Ergänzung. Mitteilungen der Schweizerischen Entomologischen Gesellschaft 60: 83-105.

Holzinger W.E., Seljak G. 2001. New records of planthoppers and leafhoppers from Slovenia, with a checklist of hitherto recorded species (Hemiptera: Auchenorrhyncha). Acta Entomologica Slovenica 9 (1): 39-66. Available on: http://www.landesmuseum.at/pdf_frei_remote/actaentslov_9_0039-0066.pdf [Accessed: December 15, 2014]

Lubiarz M., Goszczyński W., Cichocka E. 2013. Invertebrates inhabiting culinary herbs grown under cover. Journal of Plant Protection Research 53 (4): 333-337. DOI: 10.2478/ jppr-2013-0050

Maczey N., Wilson M.R. 2004. Eupteryx decemnotata Rey (Hemiptera, Cicadellidae) new to Britain. British Journal of Entomology and Natural History 17: 111-114.

Nickel H., Holzinger W.E. 2006. Rapid range expansion of Ligurian leafhopper, Eupteryx decemnotata Rey, 1891 (Hemiptera: Cicadellidae), a potential pest of garden and greenhouse herbs, in Europe. Russian Entomological Journal 15 (3): 57-63. Available on: http://kmk.entomology.ru/pdf/ rej15-2006/ent15_3\%20295_301\%20Nickel_Holzinger.pdf [Accessed: December 15, 2014]

Remane R. 1995. Zur Verbreitung einiger Zikadenarten in Mitteleuropa, insbesondere in der BRD (Homoptera: Auchenorrhyncha). Marburger Entomologische Publikationen 2 (9): 71-75.

Rung A., Halbert S.E., Ziesk D.C., Gill R.J. 2009. A leafhopper pest of plants in the mint family, Eupteryx decemnotata Rey (Hemiptera: Auchenorrhyncha: Cicadellidae), Ligurian leafhopper, new to North America. Insecta Mundi 0088: 1-4. Available on: http://journals.fcla.edu/mundi/article/ view/25180/24511 [Accessed: December 15, 2014] 